a high-resolution magnetic resonance imaging study. Arch Gen Psychiatry 1999; 56: 133-41.

39 Pantelis D, Velakoulis J, Suckling PD, McGorry LJ, Phillips AR, Yung SJ, et al. Left medial temporal volume reduction occurs during the transition from high-risk to first-episode psychosis. Schizophr Res 2000; 41: 35.

40 Lipska BK, Weinberger DR. A neurodevelopmental model of schizophrenia: neonatal disconnection of the hippocampus. Neurotox Res 2002; 4: 469-75.

41 Thompson PM, Hayashi KM, De Zubicaray GI, Janke AL, Rose SE, Semple J, et al. Mapping hippocampal and ventricular change in Alzheimer disease. Neuroimage 2004; 22: 1754-66.

42 Penadés R, Boget $\mathrm{T}$, Catalán R, Bernardo M, Gastó C, Salamero M. Cognitive mechanisms, psychosocial functioning, and neurocognitive rehabilitation in schizophrenia. Schizophr Res 2003; 63: 219-27.
43 Green MF. Cognitive impairment and functional outcome in schizophrenia and bipolar disorder. J Clin Psychiatry 2006; 67: e12.

44 Panenka WJ, Khorram B, Barr AM, Smith GN, Lang DJ, Kopala LC, et al. A longitudinal study on the effects of typical versus atypical antipsychotic drugs on hippocampal volume in schizophrenia. Schizophr Res 2007; 94 288-92.

45 Ebdrup BH, Skimminge A, Rasmussen $\mathrm{H}$, Aggernaes B, Oranje B, Lublin $\mathrm{H}$, et al. Progressive striatal and hippocampal volume loss in initially antipsychotic-naive, first-episode schizophrenia patients treated with quetiapine: relationship to dose and symptoms. Int I Neuropsychopharmacol 2011; 14: 69-82.

46 Vernon AC, Natesan S, Modo M, Kapur S. Effect of chronic antipsychotic treatment on brain structure: a serial magnetic resonance imaging study with ex vivo and postmortem confirmation. Biol Psychiatry 2011; 69: 936-44.

\title{
reflection
}

\section{W. Beers, A Mind That Found Itself}

\section{Pippa Jones}

In 1900, when he was 24, Clifford Whittingham Beers was first confined to a private mental hospital for depression and paranoia after a suicide attempt. He experienced delusions and heard frightening voices. Given that the hospital was in New Haven, Connecticut, a prosperous state, one would hope that the care was of a high standard but regrettably that was not the case.

Beers described his experiences of a total of 3 years in two private mental institutions and the state mental hospital in his groundbreaking book, A Mind That Found Itself, published in 1908. I myself have been hospitalised on three occasions, from 3 weeks' to 3 months' duration, and cannot imagine the horror of spending 3 years in hospital. Beers describes the importance of relatives and friends maintaining contact and I can echo this, visiting hours being the best part of the day. In Chapter XI, the author refers to the stigma of mental illness and one can only say that although reduced, this is still strong today.

I was somewhat taken aback by the lack of context in the book; Beers seems totally removed from anything on the national or world stage going on around him. At one point he searches in vain for newspapers from June 1900 to ascertain whether anything that set his depression off was reported. Another thing that surprised me was the absence of mention of other patients, as I have always enjoyed talking to other people on the ward. However, Beers was prepared to get into fights on behalf of one friend and he seemed to think that this conduct was justified if he verbally warned the staff first. It is interesting, 105 years after publication, that we have recently had a debate about controversial restraint techniques.

Beers describes undesirable equipment such as the muff and his first night in a strait-jacket, after which his conservator effected his transfer to the state hospital. He talked incessantly, he writes. The staff are still wanting: 'It (the curve representing my return to normality) was kept violently fluctuating ... by the impositions of those in charge of me, induced sometimes, I freely admit, by deliberate and purposeful transgressions of my own'. Medication is hardly mentioned at all, in stark contrast to the 21st century. Beers acknowledges the importance of exercise and, although he writes of his interest in art following his discharge in September 1903, this wanes and he returns to his earlier job. It made me think of the many classes I enjoyed when I was in hospital, from creative writing to relaxation, some of which I still practise. The author also refers to the chapel and I, too, found great solace in attending services and talking to the chaplaincy staff.

Beers won the support of the medical profession and other people of influence to reform the treatments of those with mental health conditions. A year after the publication of his book, he founded the National Committee for Mental Hygiene, now known as Mental Health America. 